\title{
Severe Drought Resulting from Seasonal and Interannual Variability in Rainfall and Its Impact on Transpiration in a Hill Evergreen Forest in Northern Thailand
}

\author{
Tomonori Kume*, Hideki Takizawa, Natsuko Yoshifuji, \\ Nobuaki Tanaka, Katsunori Tanaka, Chatchai Tantasirin, \\ and MASAKAZU SUZUKI
}

Our previous study revealed that a hill evergreen forest in the Kog-Ma experimental watershed in northern Thailand, which is influenced by Asian monsoon cycles, transpired actively even in the late dry season. In this study, the impact of severe drought on the transpiration of this forest was investigated using data measured at the site over 8 years that showed seasonal and interannual variation in rainfall. To this aim, the impacts of soil drought on sap flow and water potential were examined during severe drought conditions. This site showed large interannual variation in the total amount of annual rainfall and in the length of the dry period. An unusually severe drought occurred in the late dry seasons of 1998 and 2004 as a result of the small amount of annual rainfall and a prolonged dry period coinciding with El Niño. Under the detected severe drought conditions in the late dry season of 2004, noticeable symptoms of water stress were apparent only in the smallest study tree. Decreases in sap flow velocity and water potential caused by soil drought were not apparent in larger trees. Deeper root systems of larger trees may explain the lower impact of severe drought on transpiration in larger trees. Transpiration in this forest could be maintained actively even under unusually severe drought conditions.

\section{Introduction}

Deforestation in peninsular Indochina influences the regional water balance through changes in evapotranspiration (Kanae et al. 2001). Thus, to assess the effects of deforestation on the regional environment, it is first necessary to understand the processes of evapotranspiration from forests in the region. However, few studies have reported the seasonal and interannual variation in evapotranspiration and the determining factors of evapotranspiration in the Indochina region (e.g., Pinker et al. 1980; Giambelluca et al. 1996; Tanaka et al. 2003).

\footnotetext{
* Kasuya Research Forest, Kyushu University, Fukuoka, Japan E-mail: kumett@forest.kyushu-u.ac.jp
} 
Hill evergreen forest is the dominant vegetation type in northern Thailand and is influenced by the Asian monsoon (Sri-Ngernyuang et al. 2003). Our previous study revealed that the hill evergreen forest in the Kog-Ma experimental watershed in northern Thailand transpired actively even in the late dry season based on a numerical model; the model was validated with latent heat fluxes measured by the eddy covariance method (Tanaka et al. 2003). This finding implies that the seasonal trend in evapotranspiration in the hill evergreen forest type is mainly controlled by the atmospheric evaporative demand and that soil drought in the late dry season has little influence on seasonal trends in evapotranspiration. However, the impact of severe drought resulting from interannual rainfall variability on transpiration has not been investigated.

This study was undertaken to examine the impact of severe drought on transpiration in a hill evergreen forest in northern Thailand. Interannual variation in rainfall at the Kog-Ma experimental watershed was determined using continuous micrometeorological measurements, which commenced in 1997. Under the detected severe drought conditions, we assessed the impact of soil drought on sap flow and water potential in two large trees and two smaller trees. We confirmed the impact of soil drought on sap flow and water potential using a water supply treatment on an individual tree in which symptoms of water stress were apparent.

\section{Site and Measurements}

\subsection{Site}

This study was conducted in a subwatershed of the Kog-Ma experimental watershed, situated $1265-1420 \mathrm{~m}$ above mean sea level on Mount Pui $\left(18^{\circ} 48^{\prime} \mathrm{N}, 98^{\circ} 54^{\prime} \mathrm{E}\right)$ near Chiang Mai, northern Thailand. The seasonal changes in both air temperature and rainfall show that this area has three seasons: a rainy season, an early (cool) dry season, and a late (hot) dry season. The study watershed is covered with hill evergreen forest at a continuous canopy height of approximately $25-40 \mathrm{~m}$. The dominant plant family is the Fagaceae, including Lithocarpus, Quercus, and Castanopsis. The leaf area index is approximately $4.5 \mathrm{~m}^{2} \mathrm{~m}^{-2}$ with small seasonal fluctuations.

\subsection{Micrometeorological Measurements}

A 50-m-tall meteorological tower and instruments for measuring meteorological factors over the canopy have been in place at the study area since February 1997. Air temperature and relative humidity were measured at $43.4 \mathrm{~m}$ using a thermohygrograph (HMP45A; Vaisala, Helsinki, Finland). Downward and upward shortwave radiation (MS402; Eko Instruments, Tokyo, Japan) and downward and upward longwave radiation (MS201F; Eko Instruments) were measured at $50.5 \mathrm{~m}$. Volumetric soil water content $(\theta)$ was measured at depths of $0.1-0.5 \mathrm{~m}$ below the forest floor near the tower using a time domain reflectometry sensor (CS-615; Campbell Scientific, Logan, UT, USA). Data were collected every $5 \mathrm{~s}$, with 10 -min means recorded in a data logger (CR23X; Campbell Scientific). Rainfall was measured using a tipping-bucket rain gauge (20-cm diameter and $0.5-\mathrm{mm}$ tip resolution; Ohta Keiki, Tokyo, Japan) in an open space. 
TABLE 1. Characteristics of sample trees selected for measurement of water potentials and sap flows in September 2003

\begin{tabular}{|c|c|c|c|c|c|}
\hline & Family & Species & Height (m) & $\begin{array}{l}\text { Stem diameter } \\
\text { at breast height } \\
(\mathrm{cm})\end{array}$ & $\begin{array}{c}\text { Crown projected } \\
\text { area }\left(\mathrm{m}^{2}\right)\end{array}$ \\
\hline$\overline{\mathrm{CL}}$ & Lauraceae & $\begin{array}{l}\text { Cinnamomum porrectum } \\
\text { (large) }\end{array}$ & 29.8 & 51.9 & 78.1 \\
\hline LL & Fagaceae & Lithocarpus elegans & 25.4 & 28.5 & 95.9 \\
\hline LS & Fagaceae & Lithocarpus elegans & 4.8 & 4.0 & 6.7 \\
\hline CS & Lauraceae & $\begin{array}{l}\text { Cinnamomum porrectum } \\
\text { (small) }\end{array}$ & 1.4 & $1.3^{\mathrm{a}}$ & 0.4 \\
\hline
\end{tabular}

${ }^{\mathrm{a} S t e m}$ diameter at base

\subsection{Water Potential and Sap Flow Measurements}

To investigate the impact of severe drought on tree transpiration, we selected two large and two small evergreen trees that were adjacent to the tower and represented the two dominant species at this site (Table 1). Diurnal variation in the leaf water potential $\left(\Psi_{\text {leaf }}\right)$ was measured with a pressure chamber (PMS Instruments, Corvallis, OR, USA). One to three sun-exposed leaves in the upper crown of each tree were sampled every $3 \mathrm{~h}$ in the period from predawn to sunset. The measurements of stem water potential $\left(\Psi_{\text {stem }}\right)$ were substituted with the measurements of $\Psi_{\text {leaf }}$ on the branches from the lowest crown of each tree, which were artificially prevented from transpiring by covering the branches under aluminum foil and plastic bags, according to the methods of Landsberg et al. (1976). Measurements were conducted on 4-5 November 2002 (early dry season), 2-3 March 2003 (late dry season), 2-3 September 2003 (rainy season), 16-17 November 2003 (early dry season), and 7-8 March 2004 (late dry season).

At the same time, sap flow velocity was measured using a thermal heat pulse method or a stem heat balance method, depending on the stem diameter. A thermal heat pulse sensor (HP-1; Hayashi Denko, Tokyo, Japan) was inserted into the large Cinnamomum porrectum (CL), the large Lithocarpus elegans (LL), and the smaller L. elegans (LS), which had thick stems. Measurements were conducted continuously with a data logger (CR10X; Campbell Scientific). A gauge for the stem heat balance method (SGA 10; Dynamax, Houston, TX, USA) was attached to the smaller C. porrectum (CS), which had the thinnest stem, and the measurements were recorded with a data logger (CR10X) for several days before and after the water potential measurements in September 2003, November 2003, and March 2004.

\section{Results}

\subsection{Seasonal and Interannual Variability in Micrometeorological Elements}

\subsubsection{Total Amount of Annual Rainfall}

Figure 1 shows the interannual variation in rainfall at the Kog-Ma experimental watershed and rainfall records monitored by the Thai Meteorological Department 


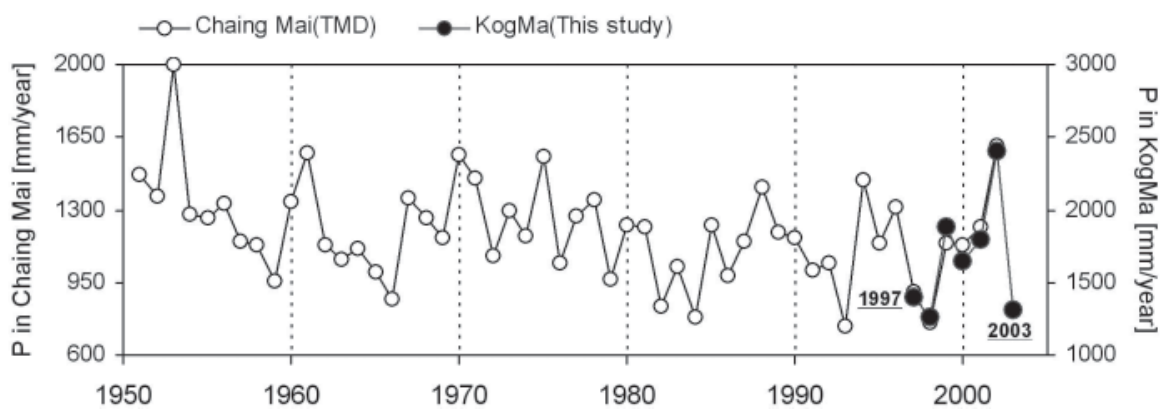

FIG. 1. Interannual variations in rainfall $(P)$ at the Kog-Ma watershed and long-term rainfall records in Chaing Mai city. Black circles represent annual rainfall measured at Kog-Ma watershed in this study; open circles represent rainfall records monitored at the nearest meteorological observatory, Thailand Meteorological Department (TMD) in Chaing Mai. Note: Rainfall in Kog-Ma is represented using the right vertical axis

(TMD) at the nearest meteorological observatory situated $312 \mathrm{~m}$ above mean sea level in Chiang Mai $\left(18^{\circ} 47^{\prime} \mathrm{N}, 98^{\circ} 59^{\prime} \mathrm{E}\right)$. The patterns of interannual variation in rainfall at the study site corresponded to the rainfall pattern recorded by the TMD, although the amount of annual rainfall recorded at the observatory was lower than at Kog-Ma, because rainfall is dependent on altitude. These data suggest that the annual rainfall at the site in 2002 was greater than in the previous 20 years and that the annual rainfall at the site in 2003 was as low as that measured in 1997 and 1998, when an unusually severe drought occurred in Southeast Asia coinciding with the El Niño event of 1997-1998 (Walsh and Newbery 1999; Wang and Weisberg 2000).

\subsubsection{General Micrometeorological Elements}

Rainfall and soil water content were generally higher from May to October (the rainy season) and lower from November to April (the dry season). Correspondingly, solar radiation and the vapor pressure deficit (VPD) were generally less from May to October (rainy season) and greater from November to April (dry season). The dry periods, defined according to Whitmore (1994) as periods with a sliding 30-day total rainfall of less than $100 \mathrm{~mm}$, appeared consistently in each year, and the dry periods never extended more than 1 month in the period from June to September (see Fig. 3a). Moreover, Fig. 3a shows large year-to-year differences in the length of the dry period, which spanned approximately 3-7 months each year. The amounts of preceding rainfall for 90 days in the late dry seasons of 1998 and 2004 were significantly lower than those in the other years because of the small annual rainfall amount and the prolonged dry period in 1997-1998 and 2003-2004. These results suggest that an unusually severe drought occurred in the late dry season of 1998 and 2004 at this site, although soil water measurements at depths of $0.1-0.5 \mathrm{~m}$ were not distinctively different in the late dry seasons of 1998, 2004, and other years (Fig. 2). A physical 

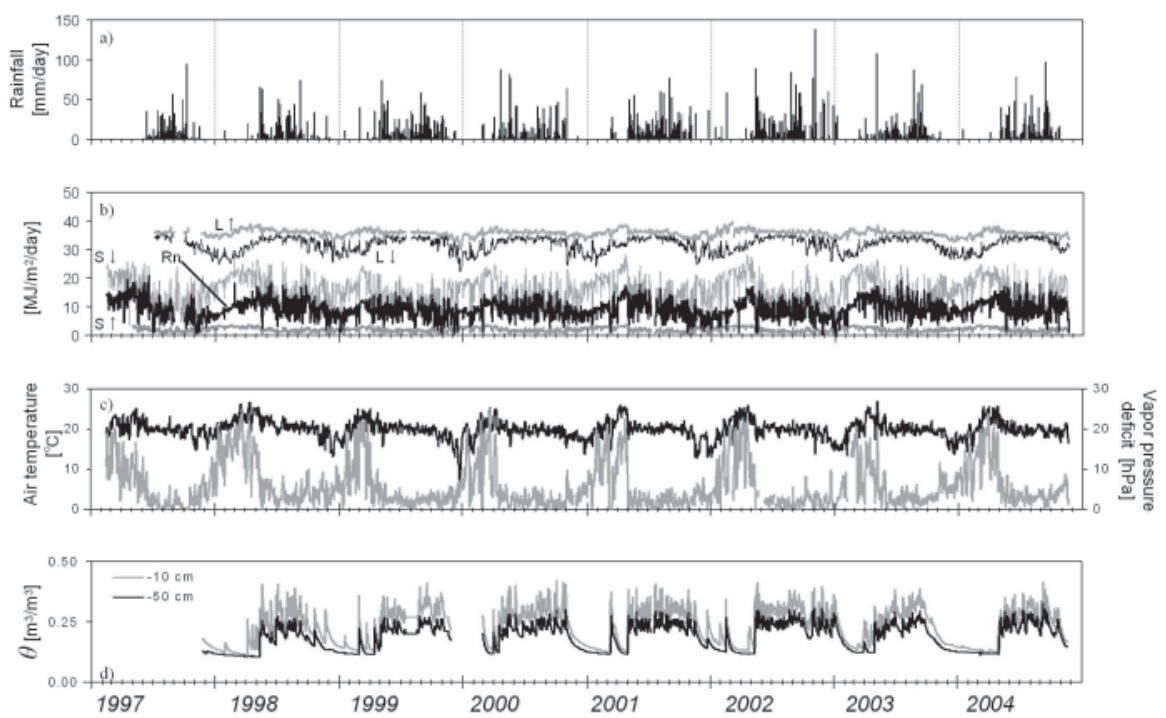

FIG. 2. Time-series daily micrometeorological elements of daily rainfall (a), downward and upward short-wave radiation $(S \swarrow, S \nearrow$, respectively), downward and upward long-wave radiation $(L \swarrow, L \nearrow$, respectively), and net radiation $(R n)(\mathbf{b})$, air temperature (black line) and vapor pressure deficit (gray line) (c), and volumetric soil water content $(\theta)$ in Kog-Ma experimental watershed, northern Thailand (d)

interpretation of the rainfall during the preceding 90 days is discussed in a later section.

\subsection{Impacts of Severe Drought on Sap Flow Velocity and Water Potential}

In this study, changes in sap flow velocity and water potential following seasonal transitions were examined in two periods: November 2002 to March 2003 (wet year) and September 2003 to March 2004 (drought year; see Fig. 3b). In both periods, diurnal peaks of the sap flow velocities in CL, LL, and LS during the late dry season were larger or very similar to the peaks from the rainy and early dry seasons (Fig. $4 \mathrm{~b}, \mathrm{c})$. The sap flow velocity peaks in CS during the late dry season were very similar to those from the early dry season, whereas the leaf fall in CS occurred in the early dry season in 2003, and the difference in these peaks in CS between rainy and early dry seasons was probably caused by leaf fall (Fig. 4c). Thus, it was difficult to detect an apparent decrease in sap flow velocities caused by severe drought even in the drought year. Further, symptoms of water stress were not apparent in the minimum $\Psi_{\text {leaf }}$ at midday in the four trees in the late dry season for both the wet and drought years, although the minimum $\Psi_{\text {leaf }}$ at midday in the four trees decreased following the seasonal transition from the rainy and early dry season to the late dry season. On the other hand, predawn $\Psi_{\text {stem }}$ in CS significantly decreased to $-1.1 \mathrm{MPa}$ in the late 

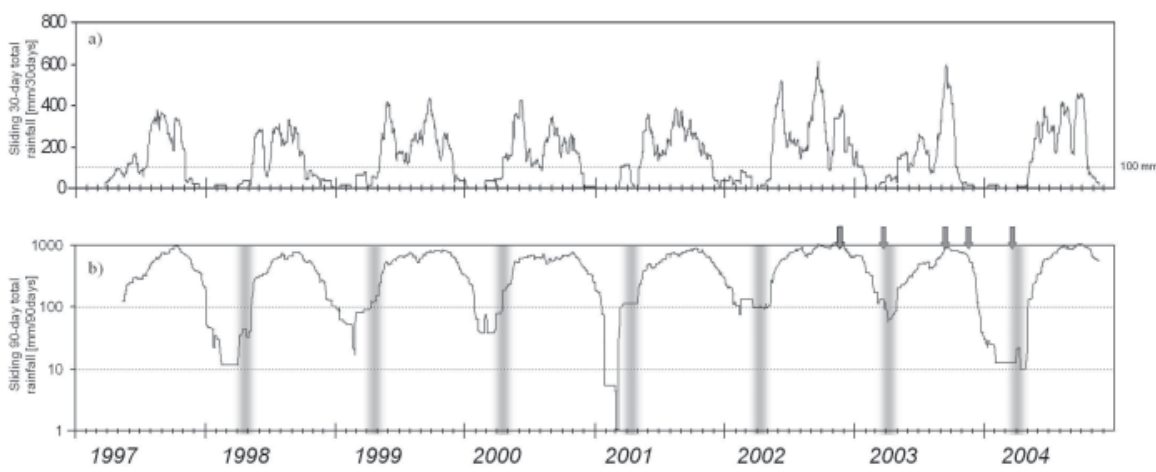

FIG. 3. Rainfall during the preceding 30 and 90 days: (a) sliding 30-day total rainfall and (b) sliding 90-day total rainfall in the period from 1997 to 2004. A period from March to April (the late dry season) is screened by a gray belt. Vertical arrows represent the timing of the water potential measurement

dry season of the drought year (Fig. 4e); this value was the lowest of any of the study specimens during the two measurement years. The predawn $\Psi_{\text {stem }}$ corresponds to the soil water potential in contact with the roots (e.g., Bucci et al. 2004). These results suggest that soil drought was more severe in the late dry season of 2004 and that CS may have suffered from soil drought.

To confirm whether CS suffered from water stress as a result of soil drought, we began supplying water to CS on 9 March 2004 (Fig. 5). After seven water supply treatments, the predawn $\Psi_{\text {stem }}$ increased from $-1.1 \mathrm{MPa}$ on 8 March to $-0.14 \mathrm{MPa}$ on 13 March, and the minimum $\Psi_{\text {stem }}$ at midday increased from $-1.3 \mathrm{MPa}$ on 8 March to $-0.4 \mathrm{MPa}$ on $13 \mathrm{March}$ (Fig. $5 \mathrm{c}$ ). The diurnal peaks in sap flow velocity also increased gradually from 9 to 13 March (Fig. 5b). The recovery of sap flow velocity and water potential in CS after water supplementation confirmed that the reductions in sap flow velocity and predawn $\Psi_{\text {stem }}$ were caused by stomatal closure due to soil drought (e.g., Davies and Zhang 1991; Meinzer et al. 1995).

Furthermore, the reduction in sap flow velocity in CS caused by soil drought ranged from $30 \%$ to $40 \%$ at a given atmospheric evaporative demand, when the reduction in sap flow velocity was defined according to Pataki et al. (2000) as follows:

$$
\text { Reduction }=1-\frac{f_{\text {late }}(\mathrm{VPD})}{f_{\text {early }}(\mathrm{VPD})}
$$

where $f_{\text {late }}(\mathrm{VPD})$ is the predicted sap flow velocity at a given VPD using the relationship between sap flow velocity and VPD in the late dry season, and $f_{\text {early }}(\mathrm{VPD})$ is the predicted sap flow velocity at a given VPD using the relationship between sap flow velocity and VPD in the early dry season. Soil drought caused reductions in sap flow velocity in CL and LL of approximately $10 \%$ and a reduction in LS of approximately $30 \%$. Thus, the degree of reduction in sap flow velocity caused by soil drought differed by tree size. However, significant reductions in sap flow velocity were not observed in the trees in the late dry season of the wet year. 

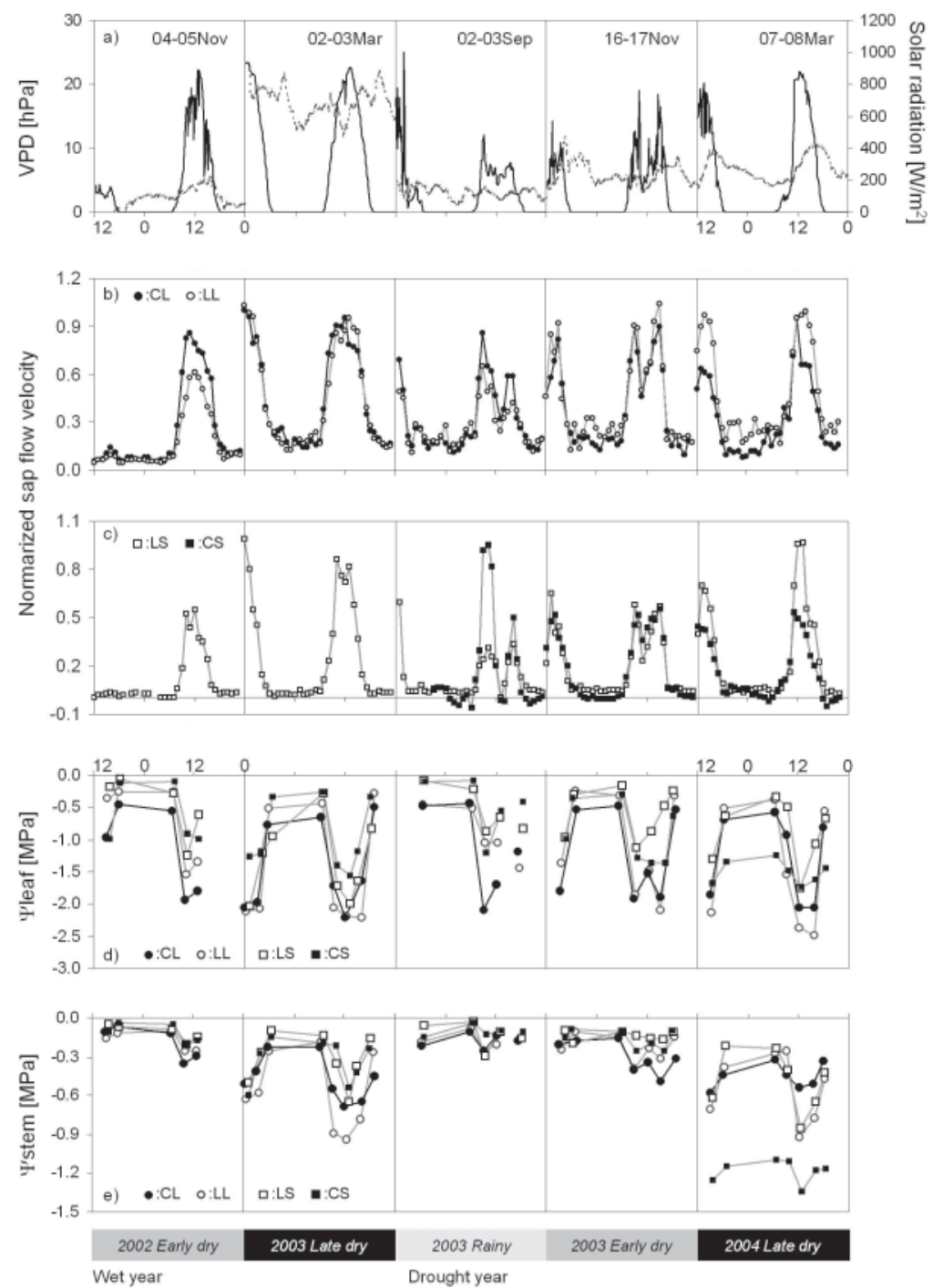

FIG. 4. Diurnal and seasonal variations in (a) solar radiation (black line) and vapor pressure deficit (dotted lines), (b) normalized sap flow velocity in large Cinnamomum porrectum (CL) (black circles) and Lithocarpus elegans (LL) (open circles), (c) normalized sap flow velocity in Lithocarpus elegans (LS) (open squares) and small Cinnamomum porrectum (CS) (black squares), (d) leaf water potentials $\left(\psi_{\text {leaf }}\right)$, and (e) stem water potentials $\left(\psi_{\text {stem }}\right)$ in four individuals. Sap flow velocities in the wet year were normalized by the maximum value in the period from November 2002 to March 2003 in each tree. Sap flow velocities in the drought year were normalized by the maximum values in the period from September 2003 to March 2004 in each tree 

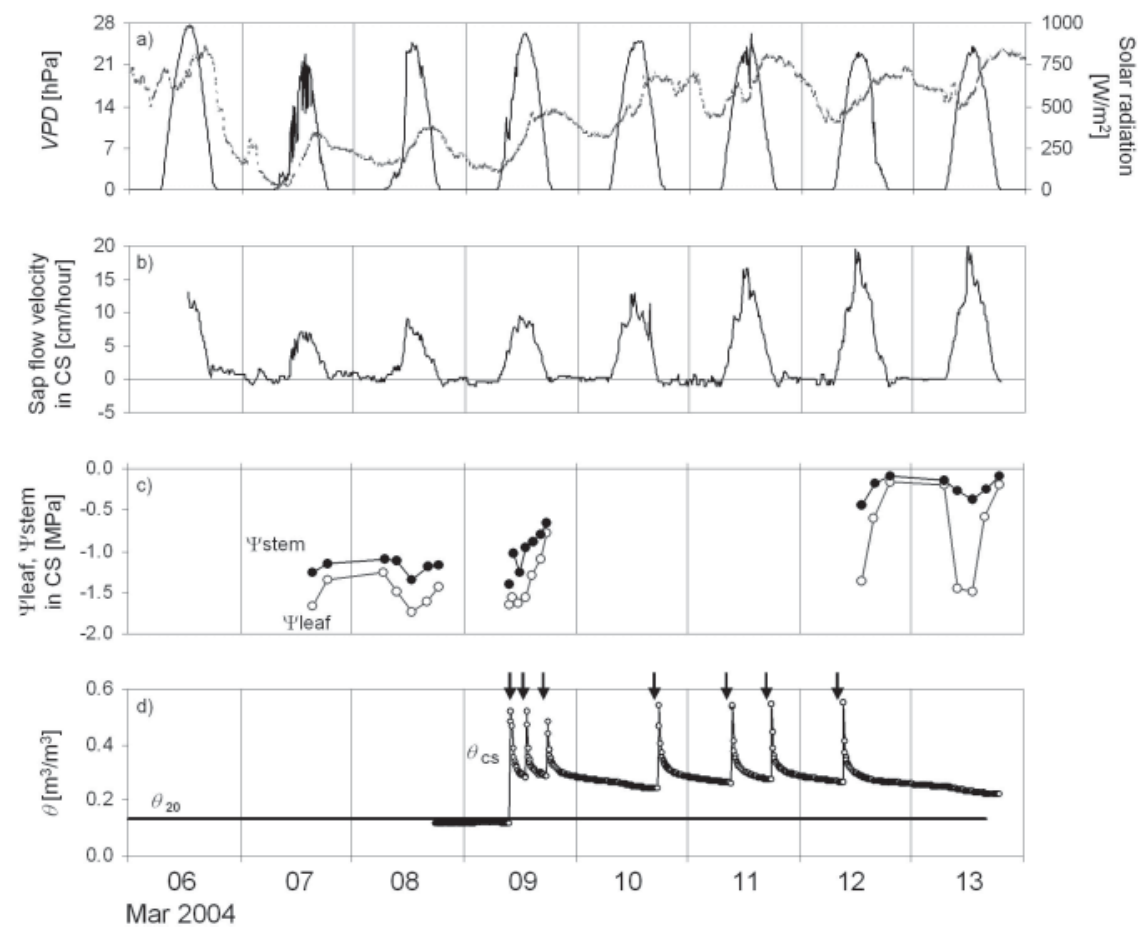

FIG. 5a-d. Recovery of sap flow and water potential in CS after water supply treatment. Diurnal variations in (a) solar radiation (black line) and vapor pressure deficit (VPD) (dotted line), (b) sap flow velocities in CS, (c) yleaf (open circles) and ystem (black circles) in CS, and (d) soil water contents measured at $20 \mathrm{~cm}$ below the ground near the tower $\left(\theta_{20}\right)$ and around CS at the depth of $20 \mathrm{~cm}\left(\theta_{\mathrm{cs}}\right)$, located about $20 \mathrm{~m}$ north of the tower. Vertical arrows represent the times at which water supply treatments were conducted

\section{Discussion}

The amount of rainfall preceding the late dry seasons of 1997 and 2004 was significantly smaller than the rainfall preceding the late dry season in the other year because of the low annual rainfall and the prolonged dry period (see Fig. 3). Under the drought conditions in the late dry season of 2004, the reductions in sap flow velocity and predawn $\Psi_{\text {stem }}$ were only significant in CS among the trees in our study (see Figs. 4, 5). The recovery of sap flow velocity and water potential in CS after water supply treatments showed that the reductions in the late dry season in the drought year were caused by stomatal closure due to soil drought. On the other hand, larger trees continued to transpire even in the late dry season of the drought year (see Fig. 4).

In this study, the sliding 90-day rainfall total was used as the index representing the degree of soil drought (see Fig. 3). For a physical interpretation of the sliding total rainfall, Fig. 6 shows the sliding total rainfall with the number of days sliding from 30 to 120 in 30 -day steps and predawn $\Psi_{\text {stem }}$ (i.e., soil water potential) for each water 


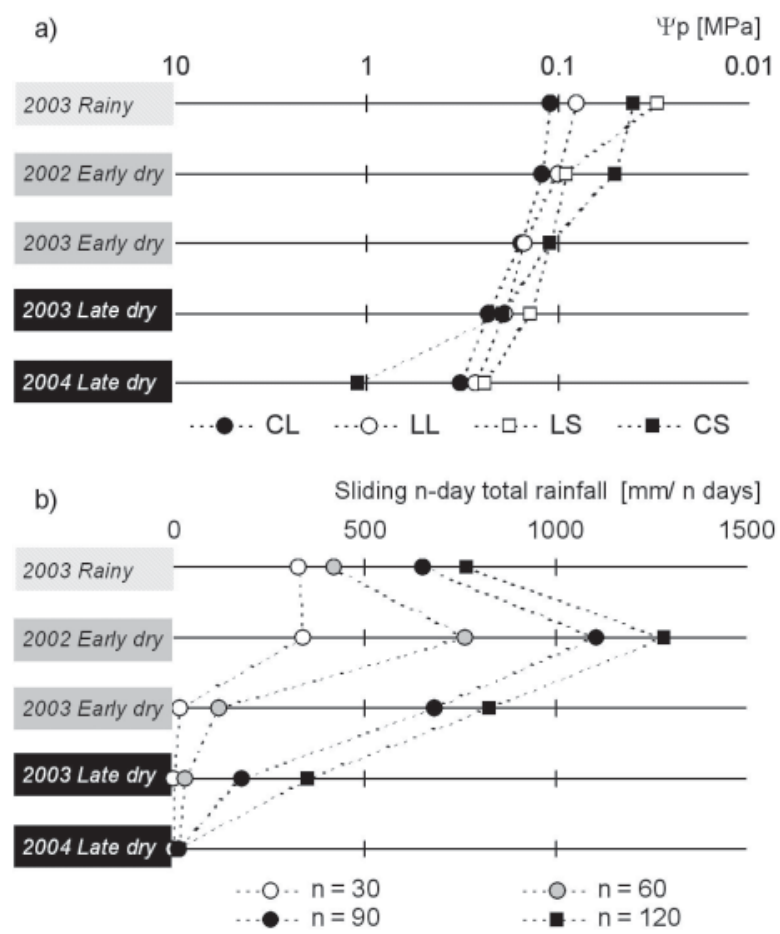

Fig. 6. Predawn $\psi$ stem $(\psi p)$ (a) and sliding n-day total rainfall (b) at each water potential measurement term. The n-day moved from 30 to 120 days in 30-day steps. Values are shown in ascending order of the average $\psi \mathrm{p}$ in four individual trees at each measurement term

potential measurement term. When the sliding total rainfall encompassed only 30 or 60 days, the tendency for soil in the late dry season to be drier in 2003 than 2004 was not evident. However, this tendency was apparent when the sliding total rainfall encompassed more than 90 days. This finding suggests that the soil condition during the late dry season is related to the amount of rainfall during the preceding 90 or more days and that the soil layer at this site has a capacity to hold rainfall from the preceding 90 or more days.

Stream flow at this site has never been interrupted, even in the late dry season (Tanaka et al. 2003), suggesting that there may be moisture deeper within the subsurface (i.e. regolith) to maintain transpiration over the late dry season. A numerical analysis using a soil-plant-atmosphere-continuum model shows that a rooting depth of more than $4-5 \mathrm{~m}$ is needed to maintain transpiration in the late dry season under unsaturated soil conditions (Tanaka et al. 2004). The possibility of trees establishing such a deep root system at this site was supported by a penetration test, which showed that the soil became harder at a depth of $4-5 \mathrm{~m}$ (Tanaka et al. 2004). The sap flow observed at the top of the watershed ridge, where the groundwater table (i.e., saturated soil water) may rarely appear, also showed active transpiration in the late dry season (N. Yoshifuji, personal communication). These results suggest that there is an 
unsaturated water reserve in the deep soil layer and that the roots in larger trees in this evergreen forest can reach this depth to maintain transpiration even in the late dry season of drought years.

A high demand for water by trees can in some cases lead to the development of a deep and extensive root system (Cermák et al. 1993). Canadell et al. (1996) showed that a tropical evergreen tree is likely to have a deep rooting depth, with the maximum ranging from 2.0 to $18.0 \mathrm{~m}$ (average, $7.3 \pm 2.8 \mathrm{~m}$ ). Such a deep root system seems to develop over decades or centuries. The roots of a small tree such as CS would likely not reach such depths. Usually, the shallower portions of soil are drier than the deeper portions during no-rain periods (e.g., Hodnett et al. 1995). The dry soil in the shallower soil layer could lead to more significant decreases in transpiration in smaller trees than in larger trees during the late dry season, particularly during unusually severe drought conditions such as those recorded at this site. The lowest predawn $\Psi_{\text {stem }}$ in CS in the late dry season of the drought year (-1.1 MPa) supports evidence that severe dry soil appeared in the shallower soil layer (see Fig. 4). On the other hand, the developed deep root system in larger trees could explain the lower impact of severe drought on transpiration in larger trees, allowing canopy-scale transpiration at this site to be maintained actively even in the late dry season of an unusually severe drought. Transpiration from larger trees is thought to contribute most to the total transpiration because of the high leaf area index of the upper canopy and the intense solar radiation and VPD to which the upper canopy is exposed.

Acknowledgments. This study was supported by CREST (Core Research for Evolution Science and Technology) of JST (Japan Science and Technology Agency). We are grateful to Professor Taikan Oki of the University of Tokyo, and to Professor Nipon Tangtham of Kasetsart University, for providing the opportunity to conduct this study. Some measurements were supported by Dr. Izumi Kosaka of Japan conservation engineers and Dr. Shoji Hashimoto of the Forestry and Forest Products Research Institute. Fruitful discussions with Mr. Norifumi Hotta and Dr. Shinji Sawano, both from the University of Tokyo, and Dr. Hikaru Komatsu of Kyushu University, are also greatly appreciated.

\section{References}

Bucci SJ, Scholz F, Goldstein G, Meinzer FC, Hinojosa JA, Hoffmann WA, Franco AC (2004) Processes preventing nocturnal equilibration between leaf and soil water potential in tropical savanna woody species. Tree Physiol 24:1119-1127

Canadell J, Jackson RB, Ehleringer JR, Mooney HA, Sala OE, Schulze E-D (1996) Maximum rooting depth for vegetation types at the global scale. Oecologia (Berl) 108:583-595

Cermák J, Matyssek R, Kucera J (1993) Rapid response of large, drought-stressed beech trees to irrigation. Tree Physiol 12:281-290

Davies WJ, Zhang J (1991) Root signals and the regulation of growth and development of plants in drying soil. Annu Rev Physiol Plant Mol Biol 42:55-76

Giambelluca TW, Tran LT, Ziegler AD, Menard TP, Nullet MA (1996) Soil-vegetationatmosphere processes: simulation and field measurement for deforested sites in northern Thailand. J Geophys Res 101:25867-25885 
Hodnett MG, Pimentel da Silva L, da Rocha HR, Cruz Senna R (1995) Seasonal soil water storage changes beneath central Amazonian rainforest and pasture. J Hydrol 170: 233-254

Kanae S, Oki T, Mushiake K (2001) Impact of deforestation on regional precipitation over the Indochina Peninsula. J Hydrometeorol 2:51-70

Landsberg JJ, Blanchard TW, Warrit B (1976) Studies on the movement of water through Apple Trees. J Exp Bot 27:79-596

Meinzer FC, Goldstein G, Jackson P, Holbrook NM, Gutierrez MV, Cavelier J (1995) Environmental and physiological regulation of transpiration in tropical forest gap species: the influence of boundary layer and hydraulic properties. Oecologia (Berl) 101:514-522

Pataki DE, Oren R, Smith WK (2000) Sap flux of co-occurring species in a western subalpine forest during seasonal soil drought. Ecology 81:2557-2566

Pinker RT, Thompson OE, Eck TF (1980) The energy balance of a tropical evergreen forest. J Appl Meteorol 19:1341-1350

Sri-Ngernyuang K, Kanzaki M, Mizuno T, Noguchi H, Teejuntuk S, Sungpalee C, Hara M, Yamakura T, Sahunalu P, Dhanmanonda P, Bunyavejchewin S (2003) Habitat differentiation of Lauraceae species in a tropical lower montane forest in northern Thailand. Ecol Res 18:1-14

Tanaka K, Takizawa H, Tanaka N, Kosaka I, Yoshifuji N, Tantasirin C, Piman S, Suzuki M, Tangtham N (2003) Transpiration peak over a hill evergreen forest in northern Thailand in the late dry season: assessing the seasonal changes on evapotranspiration using a multilayer model. J Geophys Res 108:4533

Tanaka K, Takizawa H, Kume T, Xu J, Tantasirin C, Suzuki M (2004) Impact of rooting depth and soil hydraulic properties on the transpiration peak of an evergreen forest in northern Thailand in the late dry season. J Geophys Res 109:D23107

Walsh RPD, Newbery DM (1999) The ecoclimatology of Danum, Sabah, in the context of the world's rainforest regions, with particular reference to dry periods and their impact. Philos Trans R Soc Lond B 354:1869-1883

Wang C, Weisberg RH (2000) The 1997-98 El Niño evolution relative to previous El Niño events. J Climate 13:488-501

Whitmore TC (1994) An introduction to tropical rain forests. Oxford University Press, Oxford 